\title{
Radiative forcing and climate change
}

Book or Report Section

Accepted Version

Shine, K. (2015) Radiative forcing and climate change. In: Blockley, R. and Shyy, W. (eds.) Encyclopedia of Aerospace Engineering. John Wiley \& Sons, Ltd., pp. 1-11. ISBN 9780470686652 doi: https://doi.org/10.1002/9780470686652.eae526.pub2 Available at https://centaur.reading.ac.uk/40552/

It is advisable to refer to the publisher's version if you intend to cite from the work. See Guidance on citing.

To link to this article DOI: http://dx.doi.org/10.1002/9780470686652.eae526.pub2

Publisher: John Wiley \& Sons, Ltd.

Publisher statement: This is the submitted version of K. Shine "Radiative Forcing and Climate Change" in Encyclopedia of Aerospace Engineering, eds R. Blockley and W. Shyy, John Wiley: Chichester. DOI: 10.1002/9780470686652.eae526.pub2 which has been published in final form on

http://onlinelibrary.wiley.com/book/10.1002/9780470686652

All outputs in CentAUR are protected by Intellectual Property Rights law, including copyright law. Copyright and IPR is retained by the creators or other copyright holders. Terms and conditions for use of this material are defined in the End User Agreement.

www.reading.ac.uk/centaur 
Central Archive at the University of Reading

Reading's research outputs online 
Prepared for the Encylopedia of Aerospace Engineering

\section{Reference: EAE526.PUB2}

Professor Keith P Shine FRS, Department of Meteorology, University of Reading, Earley Gate, Reading RG6 6BB, UK

email: k.p.shine@ reading.ac.uk Tel: 01183788405 Fax:0118 3788905

Prepared in Microsoft Word 2007

Figure files:

aerospace_aea526_pub2_fig1.tif

aerospace_aea526_fub2_fig2.gif

This is the submitted version of

K. Shine "Radiative Forcing and Climate Change" in Encyclopedia of Aerospace Engineering, eds R. Blockley and W. Shyy, John Wiley: Chichester. DOI: 10.1002/9780470686652.eae526.pub2 which has been published in final form on http://onlinelibrary.wiley.com/book/10.1002/9780470686652

\section{RADIATIVE FORCING AND CLIMATE CHANGE}

Keith P. Shine

Department of Meteorology

University of Reading

Reading, United Kingdom

Keywords: Radiative forcing, carbon dioxide, climate change, global warming potential, global temperature-change potential

\section{Abstract}

Aviation causes climate change as a result of its emissions of $\mathrm{CO}_{2}$, oxides of nitrogen, aerosols and water vapour. One simple method of quantifying the climate impact of past emissions is radiative forcing. The radiative forcing due to changes in $\mathrm{CO}_{2}$ is best characterised, but there are formidable difficulties in estimating the non- $\mathrm{CO}_{2}$ forcings - this is particularly the case for possible aviation-induced changes in cloudiness (AIC). The most recent comprehensive assessment gave a best-estimate of the 2005 total radiative forcing due to aviation of about 55 to $78 \mathrm{~mW} \mathrm{~m}^{-2}$ depending on whether AIC were included or not, with an uncertainty of at least a factor of two,. The aviation $\mathrm{CO}_{2}$ radiative forcing represents about $1.6 \%$ of the total $\mathrm{CO}_{2}$ forcing from all human activities. It is estimated that, including the non- $\mathrm{CO}_{2}$ effects, aviation contributes between 1.3 and $14 \%$ of the total radiative forcing due to all human activities. Alternative methods for comparing the future impact of present-day aviation emissions are presented - the perception of the relative importance of the non- $\mathrm{CO}_{2}$ emissions, relative to $\mathrm{CO}_{2}$, depends considerably on the chosen method and the parameters chosen within those methods. 


\section{INTRODUCTION}

The possibility that aviation could contribute to climate change was considered in the earliest assessments of the climate impact of human activity (e.g., Matthews, Kellogg and Washington, 1971). In the subsequent period, considerable attention focused on examining the impact of possible future supersonic fleets on stratospheric ozone; aviation's impact on climate took a back seat. The European assessment by Brasseur et al. (1998) gave renewed vigour to the appraising the climate influence. This was followed by the wider-ranging report on "Aviation and the Global Atmosphere" by the Intergovernmental Panel on Climate Change (IPCC, 1999), which remains a basic reference. Lee et al. $(2009,2010)$ have provided updated assessments.

\section{CONCEPTUAL FRAMEWORK}

\subsection{Radiative forcing}

The planetary energy balance can be characterised as a balance between two components: solar radiation (which is mostly at wavelengths less than $4 \mu \mathrm{m}$ ) absorbed or reflected back to space by the Earth and its atmosphere, and longwave (thermal-infrared) radiation (which is mostly at wavelengths greater than $4 \mu \mathrm{m}$ ) emitted and absorbed by the Earth's surface and atmosphere.

At the top of the atmosphere, averaged over the globe and over a year, there is a close balance between the absorbed solar radiation (ASR) by the Earth system and the outgoing longwave radiation (OLR), so that the net radiation (NET)

$$
\mathrm{NET}=\mathrm{ASR}-\mathrm{OLR} \approx 0 .
$$

Satellite observations show that the global and annual mean ASR and OLR are both about $240 \mathrm{~W} \mathrm{~m}^{-2}$ (e.g., Hartmann, 1996).

The main mechanisms which drive climate change perturb either or both the ASR or the OLR, so that NET $\neq 0$. More precise definitions are available (e.g., Myhre et al., 2013), but the size of the initial perturbation of NET, say following a change in $\mathrm{CO}_{2}$ concentration, is a useful working definition of the radiative forcing (RF) of climate change. RF provides a useful first-order indication of the size of different climate change mechanisms and it will be a major focus here.

Unless otherwise stated, RF is taken here to refer to its global-average value. RF can refer to the change in NET over any specified period of time. Forcing due to human activity is often reported as the total change since some "pre-industrial" time, for example since 1750. For aviation, the total present-day forcing has occurred over a much shorter period, as emissions were negligible prior to 1940 (e.g., Lee et al., 2009).

\subsection{Temperature response and climate sensitivity}

When RF is positive the planet is absorbing more energy than it is emitting (and vice versa if RF is negative); the climate system responds by warming, leading to more infrared emission and hence a higher OLR. Given sufficient time (and assuming that 
$\mathrm{RF}$ is not time varying), the system will reach a new equilibrium, where NET is once again close to zero.

The simplest representation of the response of the climate system to a radiative forcing is given by Hartmann (1996) and Fuglestvedt et al., (2010)

$$
C \frac{d \Delta T(t)}{d t}=R F(t)-\frac{\Delta T(t)}{\lambda}
$$

where $t$ is time, $\mathrm{C}$ is the heat capacity of the climate system (most of which is contained within the ocean) $\left[\mathrm{J} \mathrm{K}^{-1} \mathrm{~m}^{-2}\right], \Delta T$ is the departure of the global-mean surface temperature $[\mathrm{K}]$ from its unperturbed value, and $\lambda$ is the climate sensitivity parameter $\left[\mathrm{K}\left(\mathrm{W} \mathrm{m}^{-2}\right)^{-1}\right]$.

A useful special case is when RF is independent of time. The solution to Equation (2) is then

$$
\Delta T(t)=\lambda R F[1-\exp (-t / \lambda C)]
$$

As $t$ tends to infinity, the equilibrium surface temperature $\Delta T_{e q}$ is given by

$$
\Delta T_{e q}=\lambda \mathrm{RF}
$$

Hence, Equation (4) tells us that $\Delta T_{e q}$ resulting from a (constant) radiative forcing is simply the product of that forcing and the climate sensitivity parameter. This equation provides much of the justification for using RF as an indicator of climate change.

Equation (3) shows that the product of $\lambda$ and $C$ defines a time constant for the climate system to respond to an RF and is of order a few decades; a precise number cannot be given, because of uncertainties in the value of $\lambda$ (see below) and the value of $C$ is not well-defined, as it depends on the rate at which heat is transferred from the surface layers of the ocean to the deep ocean.

\subsection{Climate feedbacks}

The value of $\lambda$ is a chronic uncertainty in climate change science. If the Earth and atmosphere emitted to space as a black-body, Stefan's Law would give the OLR as $\sigma T_{e}^{4}$ where $\sigma$ is the Stefan-Boltzmann constant and $T_{e}$ is an effective emitting temperature of the climate system. In this case, the first derivative of Stefan's Law is $4 \sigma T_{e}^{3}$, and its reciprocal would give $\lambda$. For an OLR of $240 \mathrm{~W} \mathrm{~m}^{-2}, \lambda$ would be about $0.3 \mathrm{~K}\left(\mathrm{~W} \mathrm{~m}^{-2}\right)^{-1}$, indicating that the planet would warm up by $0.3 \mathrm{~K}$ for each $\mathrm{W} \mathrm{m}^{-2}$ of forcing. This is sometimes referred to as the "black-body" or "no-feedback" response.

However, as the Earth warms (or cools) a number of feedback processes occur that alter the radiative properties of the atmosphere and surface. For example, in response to a positive RF, a warmer atmosphere can contain more water vapour; water vapour is a greenhouse gas and hence this further enhances the warming - giving a positive feedback. Similarly, a warmer planet would be expected to have a decreased extent of snow and ice - this would decrease the amount of solar radiation reflected back to space leading to a further warming. These two feedbacks are believed to be relatively 
well understood (e.g., IPCC, 2013); together they approximately double the value of $\lambda$ from its black-body value.

From the late 1970s it was recognised that numerical climate models developed in different laboratories gave significantly different values for $\lambda$. It is now understood that the prime reason for this is the way that these models represent the response of clouds to climate change. A principal difficulty is that climate models represent the Earth's climate on a horizontal grid of order of $100 \mathrm{~km}$ spacing - many important climate processes, including those that control clouds, occur on much smaller spatial scales, and these have to be related in some way to the variables (such as temperature and humidity) that are represented on the model grid. An additional difficulty has been that many important parameters describing clouds (such as the amount of cloud ice) had not been observed globally; it had been difficult to verify the quality of a climate model's representation of clouds. A new generation of satellite instruments is starting to greatly improve this situation (e.g., Boucher et al., 2013).

Clouds strongly influence OLR and ASR and have the potential to be a powerful feedback mechanism. Many cloud characteristics influence OLR and ASR - for example, cloud amount, height, thickness, and the proportion that is ice or water. Any or all these could change as climate changes and even if climate models have a faithful representation of present-day clouds, this does not guarantee that they can faithfully represent changes in properties. The most recent IPCC scientific assessment (IPCC, 2013) reports that $\lambda$ is likely to lie in the range from about 0.4 to $1.2 \mathrm{~K}$ (W $\left.\mathrm{m}^{-2}\right)^{-1}$; this indicates that climate models vary from having a weak to a strong positive cloud feedback.

There are many other possible climate feedbacks (IPCC, 2013) - for example, climate change can impact the way the oceans and land take up $\mathrm{CO}_{2}$. The so-called carbonclimate feedback is an important focus of current research, and may be a significant positive feedback.

\subsection{Limitations in the use of radiative forcing}

Several caveats are necessary in using Equation (4) (see also Myhre et al., (2013)). It was originally thought that the value of $\lambda$ was approximately independent of the nature of the climate change mechanism. So, for example, if RF was due to a change in the output of the Sun (which influences the ASR) the value of $\lambda$ would be the same as for changes in $\mathrm{CO}_{2}$ (which mainly influences the OLR). More recent calculations now show that $\lambda$ varies significantly amongst climate change mechanisms. This effect can be characterised by an "efficacy", defined as the ratio of $\lambda$ for the given climate change mechanism, to $\lambda$ for a $\mathrm{CO}_{2}$ doubling. Ponater et al. (2006) present efficacies for a range of aviation-induced RFs. To be confident that efficacies are robustly known, careful comparison of results from similar experiments with different climate models is necessary - no consensus yet exists; it is assumed here that all climate change mechanisms possess the same value of efficacy. Once a consensus emerges, it would be better to compare climate change mechanisms using the product of efficacy and RF, or else (as proposed in Myhre et al., (2013)) to use a variant of the RF called the "effective RF". 
1 A second caveat is that Equation (4) refers strictly to global-mean quantities. This is

2 important, for two reasons. Firstly, Equation (4) cannot be applied locally - the value

3 of RF at a given location is not a good indicator of the temperature response at that

4 location. This is because winds and ocean currents transport heat around the planet -

5 the geographical pattern of response is more strongly determined by the nature of the

6 feedbacks than the distribution of the forcing (e.g., Boer and Yu, 2003; IPCC, 2013).

7 For example, snow/ice feedback leads to a greater response at higher latitudes.

8 Secondly, it is easy to imagine cases where the global-mean RF is zero (due to chance

9 compensation between mechanisms causing positive and negative RF) - even though

10 the global-mean temperature change may be close to zero, significant local climate

11 change could still occur.

The final caveat discussed here, is that there are many other dimensions to climate change beyond RF and $\Delta T$ - for example, changes in precipitation, extreme storms, sea level rise, which are also important in terms of impact on society. These are represented in the more complex models, but not in the simpler representations encapsulated by Equation (2).

Most of the work on aviation and climate change has concentrated on calculating RF and hence RF will be the focus here.

\section{RADIATIVE FORCING DUE TO AVIATION}

The RF due to the accumulated emissions from aviation is summarized in Figure 1, from Lee et al. (2009), the most recent detailed assessment. The total size of each bar gives the best estimate RF for 2005, relative to pre-industrial times, with the numerical value shown in the first column on the right hand side. The white line shows the value estimated in Forster et al. (2007) (which is repeated in parentheses in the first column on the right hand side). The error bar represents the $90 \%$ likelihood range, which comes from a mixture of the range of published values and expert judgement. The middle column on the right hand side indicates the spatial scale of the forcing. The final column gives the level of scientific understanding (LOSU), based on expert judgement, taking into account the difficulties in calculating the forcing. Figure 2 illustrates typical latitudinal distributions of many of these forcings.

It would, of course, be desirable if these RFs could be observed directly. It is only rarely that this is possible (for example, the effect of large volcanic eruptions or changes in the sun's output, which has only become possible relatively recently with the advent of satellite-based observations). There are various reasons for this. Firstly, the deviations in NET due to RF are relatively small and their detection would require a long sequence of well-calibrated satellite observations. Secondly, any observed variation in NET is due to both RF and the response of the climate to that forcing and it is difficult to untangle these. Thirdly, in this context, even if RF could be observed, it would be difficult to unravel how much is due to aviation and how much is due to other human activity - as will be shown, the effects of aviation are only a small percentage of the total. As a result, RF calculations generally depend heavily on computer simulations - in addition to uncertainties due to an incomplete understanding of atmospheric processes, calculations are reliant on assumed distributions of emissions of $\mathrm{CO}_{2}$ and other gases and particles from aviation - there 
are significant differences in these distributions in recent inventories (e.g., Wilcox et al., 2013).

It is important to note that aviation-induced effects have a wide variety of different timescales. For $\mathrm{CO}_{2}$, a significant fraction (several 10's of \%) of any perturbation, as a result of an aviation (or any other) emission, persists in the atmosphere for thousands of years (Archer and Brovkin, 2008; IPCC, 2013) - this is because of the way $\mathrm{CO}_{2}$ changes lead to changes in the oceanic carbon cycle. Hence, the $\mathrm{CO}_{2} \mathrm{RF}$ in Figure 1 results from emissions over the entire time-period that aircraft have been emitting. At the other extreme, contrails typically persist for at most a few hours. Hence the entire $\mathrm{RF}$ due to linear contrails is a result of very recent aviation activity. One consequence of these different timescales is to consider the hypothetical case in which all aviation emissions suddenly cease. The RF due to linear contrails would disappear almost immediately; the $\mathrm{CO}_{2} \mathrm{RF}$ would persist for centuries. These issues of timescale will be considered again in Section 4. There has been no consolidated update of Figure 1 in the recent literature, but changes due to improved understanding will be indicated in the sections below.

\subsection{Carbon dioxide}

$\mathrm{CO}_{2}$ is an effective greenhouse gas as it possesses strong absorption bands at thermalinfrared wavelengths, notably near $15 \mu \mathrm{m}$. On a per molecule basis, $\mathrm{CO}_{2}$ is relatively weak, partially because of the large natural $\mathrm{CO}_{2}$ concentrations. However, this relative weakness is compensated by the fact that the absolute changes in $\mathrm{CO}_{2}$ concentration are much higher than those of other greenhouse gases emitted by human activity.

$\mathrm{CO}_{2}$ is the easiest of all aviation forcings to consider; its lifetime in the atmosphere (decades to millennia) is so long, that there is essentially no climate difference between $\mathrm{CO}_{2}$ produced from burning kerosene in a jet engine to $\mathrm{CO}_{2}$ produced from burning any fossil fuel, anywhere else in the globe. The timescales over which the winds spread out any $\mathrm{CO}_{2}$ emission across the planet (many months) are much shorter than the lifetime of the $\mathrm{CO}_{2}$ in the atmosphere.

Figure 1 shows that the estimated $\mathrm{CO}_{2} \mathrm{RF}$ from aviation emissions up to 2005 is 28 $\mathrm{mW} \mathrm{m}{ }^{-2}$, with a high LOSU and it is clearly one of the largest single components. The value for 2011 is likely to be about 10-15\% higher because of growth in emissions. Figure 2 shows that the forcing is global in extent.

\subsection{Oxides of nitrogen}

The emission of oxides of nitrogen $\left(\mathrm{NO}_{\mathrm{x}}\right)$ by aviation leads to a complex chain of chemical effects (see eae347.pub2), making the evaluation of the net RF challenging. $\mathrm{NO}_{\mathrm{x}}$ causes an increase in ozone. Ozone absorbs ultra-violet and visible radiation and has thermal-infrared absorption bands, notably at wavelengths near $10 \mu \mathrm{m}$. This ozone forcing is positive; Figure 1 shows this forcing is, within the uncertainty bars, the same size as the $\mathrm{CO}_{2}$ forcing, although more recent analyses indicate that it may be around 20\% smaller (e.g., Søvde et al., 2014).

The ozone change has a knock-on effect in increasing the concentration of the hydroxyl radical, $\mathrm{OH}$, which plays a key role in controlling the concentrations of 
many atmospheric species. In the context of climate change, the most important is methane $\left(\mathrm{CH}_{4}\right)$, which is a powerful greenhouse gas (about 24 times $\mathrm{CO}_{2}$ on a per molecule basis) - more $\mathrm{OH}$ means that $\mathrm{CH}_{4}$ is more readily destroyed, and hence $\mathrm{CH}_{4}$ concentrations are reduced. (Methane concentrations have increased since preindustrial times (e.g., Myhre et al., 2013) as a result of all human activity, but $\mathrm{NO}_{\mathrm{x}}$ emissions are believed to have reduced that rate of increase.) Hence the $\mathrm{CH}_{4}$ reduction by aviation causes a negative RF which Figure 1 shows to be around $50 \%$ of, but opposite in sign to, the ozone forcing.

There are several further consequences of the $\mathrm{CH}_{4}$ reduction (e.g., Myhre et al., 2013). One of these is that methane itself is important for ozone formation; the loss of methane leads to an ozone reduction which offsets the ozone increase generated by the $\mathrm{NO}_{\mathrm{x}}$ increase. Several recent publications (e.g., Søvde et al., 2014) indicate the net effect of aviation $\mathrm{NO}_{\mathrm{x}}$ emissions is smaller than indicated in Figure 1, at around 5( \pm 4$)$ $\mathrm{mW} \mathrm{m} \mathrm{m}^{-2}$, because of improved understanding of atmospheric processes.

There are additional complications concerning $\mathrm{NO}_{\mathrm{x}}$. Firstly, the impact on ozone depends strongly on the altitude and latitude where $\mathrm{NO}_{\mathrm{x}}$ is emitted. The values in Figure 1 refer to the present-day fleet, concentrated as it is in the northern midlatitudes in the upper troposphere and lower stratosphere. If the height or geographical distribution of emissions changes, so too could the $\mathrm{NO}_{x}$ RF. Secondly, while the $\mathrm{O}_{3}$ and $\mathrm{CH}_{4}$ forcings cancel to some extent in the global mean, they do not do so locally. Figure 2 shows that the ozone forcing, for the present-day fleet, is concentrated in northern mid-latitudes; by contrast, because $\mathrm{CH}_{4}$ is relatively long lived (with a lifetime of 10 years), the reduction spreads across the globe, and is roughly equal in both hemispheres. Hence, in the northern hemisphere, the positive ozone forcing dominates, while in the southern, the negative $\mathrm{CH}_{4}$ forcing dominates. This is an example of where an apparently small global-mean forcing may still lead to a significant regional climate impact.

\subsection{Water vapour}

Burning kerosene leads to water vapour being emitted by aviation. Water vapour is a strong greenhouse gas and the main contributor to the natural greenhouse effect. Aviation water vapour emissions within the troposphere are not believed to lead to any significant concentration changes - the vigour of the natural hydrological cycle is such that the lifetime of water vapour molecules is around 7 days, and it is not possible to accumulate large changes in concentration. However, in the stratosphere, the lifetime is considerably longer (many months) allowing more marked changes to occur. The tropopause, which separates the troposphere from the stratosphere, varies with location, season and with particular weather systems, but broadly varies from around $8 \mathrm{~km}$ in high latitudes to $16 \mathrm{~km}$ in the tropics. The civil aviation fleet spends a considerable amount of time in the lower stratosphere (e.g., Gauss et al., 2003) especially during northern-hemisphere winter when, on average, the tropopause is lower in altitude.

Figure 1 shows that the water vapour RF to be modest $\left(3 \mathrm{~mW} \mathrm{~m}^{-2}\right)$ and an order of magnitude smaller than $\mathrm{CO}_{2}$. More recent assessments (e.g., Wilcox et al., 2012) indicate it could be smaller still $\left(1 \mathrm{~mW} \mathrm{~m}^{-2}\right.$, with a likely upper limit of $\left.1.4 \mathrm{~mW} \mathrm{~m}^{-2}\right)$. However, as discussed in IPCC (1999), were future fleets of supersonic aircraft to fly 
in the stratosphere, water vapour might become the dominant RF, as most of the emissions would occur at altitudes where its lifetime is long.

\subsection{Aerosol}

Aerosol particles emitted by aircraft engines, or forming within the exhaust plume, can influence RF by absorbing and/or scattering solar radiation; they are generally too small (being sub-micron in size) to significantly influence thermal-infrared radiation.

Sulphate aerosols are generally non-absorbing, especially at visible wavelengths; they cause an RF by scattering solar radiation, and hence exert a negative RF. Figure 1 shows a small RF $\left(-5 \mathrm{~mW} \mathrm{~m}^{-2}\right)$. By contrast, soot particles are highly absorbing at visible wavelengths and absorb solar radiation that would otherwise be scattered to space. Hence they exert a positive RF which is roughly equal in size $\left(3 \mathrm{~mW} \mathrm{~m}^{-2}\right)$, but opposite in sign to the sulphate forcing. Recent simulations (Gettelman and Chen, 2013; Righi et al., 2013) are broadly supportive of values of around this size.

This indicates that aerosols are not a major direct contributor to aviation RF. Nevertheless, they play an important role in contrail formation (see eae352.pub2) and may significantly alter the properties of natural clouds. These topics are covered in the following sub-sections.

\subsection{Contrails}

Aircraft contrails are, arguably, the most obvious visible sign of human activity on the atmosphere, especially for those living beneath busy flight tracks. Of interest here are so-called persistent contrails, which form when an aircraft flies through a sufficiently cold layer which is supersaturated with respect to ice (see eae352.pub2). These contrails may last for a few hours.

There are many difficulties in estimating the RF due to contrails. Firstly, although contrails can be clearly seen in satellite images, reliable global climatologies of their horizontal coverage have not yet been developed. This requires pattern-recognition techniques that can reliably distinguish contrails from other clouds. To date detailed analysis of satellite images are available over more restricted areas and time periods. These are then used together with modelling techniques (which combine meteorological data and flight inventories) to provide a global estimate of contrail occurrence. Typical estimates are that, on a global average, about 0.05 to $0.1 \%$ of the sky is covered by contrails at any one time (e.g. Myhre and Stordal, 2001; Spangenberg et al., 2013).

A second difficulty is that RF calculations require additional information on contrail properties, such as their thickness, and the number, size and shape of the ice crystals that make up the contrail. Data is available only for a limited number of case studies and many assumptions must be made for global calculations.

The final difficulty discussed here concerns the fact that the net contrail RF is a small residual of opposing longwave and shortwave RF. Contrails reflect solar radiation, causing a negative RF, and trap thermal-infrared radiation decreasing the $O L R$ and causing a positive RF. 
On an annual and global average, it is believed that the thermal-infrared RF dominates - Figure 1 indicates a global and annual mean RF of around $12 \mathrm{~mW} \mathrm{~m}^{-2}$; a number of other recent studies have derived values of $10 \mathrm{~mW} \mathrm{~m}^{-2}$ or less (e.g., Boucher et al., 2013; Burkhardt and Kärcher 2011; Spangenberg et al., 2013).

Because contrails are so short-lived, they persist only in areas of high aircraft traffic, and hence the resulting forcing is also very inhomogeneous (Figure 2). Also, the contrail forcing varies significantly during the day, as the compensation between the thermal-infrared and the shortwave RF depends on the availability of sunlight (Myhre and Stordal 2001; Stuber et al., 2006). Thus at night, the thermal-infrared RF is the only component, whilst in the day, the net forcing can be negative, if the shortwave RF dominates. It has not yet been established whether this day-night difference significantly influences the climatic effect of contrails.

The simulations of Ponater et al. (1996) and Rap et al. (2010) indicate that contrail RF may be less effective at causing a surface temperature change because their efficacy (see Section 2.4) may be significantly less ( 0.6 and 0.3 respectively) than that of $\mathrm{CO}_{2}$. It will be important to see if further simulations find similarly low values.

There were claims of a clear climatic effect, resulting from the absence of contrails, following the grounding of US civil aircraft, after the 9/11 terrorist attacks (Travis $e t$ al., 2004). These conclusions have been robustly challenged by a number of studies (e.g., Deitmuller et al., 2008).

\subsection{Aviation-induced cloud changes}

Aviation-induced cloud (AIC) changes are probably the most uncertain aviation RF but have the potential to be one of the most important.

Following Lee et al. (2009), two distinct AIC effects are discussed. First, persistent contrails (see Section 3.5) can spread to form cirrus-like clouds which seem indistinguishable from natural cirrus clouds - this is referred to here as the direct AIC forcing. There is clear evidence that contrails do evolve into cirrus-like clouds (e.g., Minnis et al., 1998). The many difficulties in quantifying this forcing include the problem of knowing whether natural cirrus clouds would have formed in any case, whether the aviation emissions impact on natural cirrus, and defining the properties of the AIC (e.g., Burkhardt and Kärcher, 2011). The mid-range estimate for this RF of $30 \mathrm{~mW} \mathrm{~m}^{-2}$ (see Figure 1) has been revised upwards to $40 \mathrm{~mW} \mathrm{~m}^{-2}$ for 2011 , in IPCC's recent assessment (Boucher et al., 2013) making it the largest single aviationinduced RF. However the uncertainty in this estimate is around a factor of three, indicating low confidence.

Second, sulphate aerosols due to surface-based emissions may cause a significant negative RF by influencing the properties of low-altitude clouds (e.g. Boucher et al., 2013). Sulphate and black carbon aerosols from aviation could have a similar effect. There are formidable difficulties in performing such calculations because of uncertainties in microphysical processes in clouds and how they are affected by changing aerosol concentrations. Nevertheless recent modelling studies indicate that the effect of sulphate emissions on clouds might cause a negative RF of several tens 
of $\mathrm{mW} \mathrm{m}^{-2}$ (Righi et al., 2013; Gettelman and Chen, 2013). This would make it almost as important as, but opposite in sign to, the direct AIC RF; much further work is clearly necessary.

\subsection{Summary and comparison with the total impact of human activity.}

Figure 1 shows the total RF in 2005 due to aviation both excluding $\left(55 \mathrm{~mW} \mathrm{~m}^{-2}\right)$ and including $\left(78 \mathrm{~mW} \mathrm{~m}^{-2}\right)$ the central estimate for the direct AIC RF. This indicates that the total aviation RF is between 2 or 3 times the aviation $\mathrm{CO}_{2} \mathrm{RF}$ alone, although the level of scientific understanding is low for the total forcing. Growth in aviation emissions and recent research on the RF due to $\mathrm{NO}_{\mathrm{x}}$ and the effect of sulphate emissions on clouds, would likely lead to broadly similar figures for the $2011 \mathrm{RF}$ but a detailed assessment is not yet available.

These numbers can be compared to estimates of the total RF due to human activity (Myhre et al., 2013) for 2011 relative to pre-industrial times. The total $\mathrm{CO}_{2} \mathrm{RF}$ is estimated to be $1.8 \mathrm{~W} \mathrm{~m}^{-2}$ ( $\pm 10 \%$, with high level of scientific understanding), with the total RF due to human activity of about $2.3 \mathrm{~W} \mathrm{~m}^{-2}$; the uncertainty in this value is about $50 \%$.

Lee et al. (2009) estimate that aviation $\mathrm{CO}_{2}$ currently contributes around $1.6 \%$ of the total anthropogenic $\mathrm{CO}_{2} \mathrm{RF}$, while the total aviation $\mathrm{RF}$ is $3.5 \%$ without or $4.9 \%$ with the direct AIC RF. Lee et al. (2009) present results from Monte Carlo simulations using uncertainty estimates and find the $90 \%$ uncertainty ranges of the contribution of aviation to the total anthropogenic RF range from 1.3 to $10 \%$ if direct AIC RF is excluded, and from 2 to $14 \%$ if the direct AIC RF is included.

No attempt is made here to provide projections of the future contribution of aviation to total RF but this is discussed in Lee et al. (2009). Many factors inhibit a confident prediction. The total anthropogenic RF depends heavily on future changes in population, economic growth and technological developments and the extent to which any international climate treaties influence emissions. The aviation RF depends on such developments and also depends on whether any changes to the operation of the present and future fleets (e.g. cruise altitude) occur.

\section{EMISSION INDICES}

\subsection{General considerations}

The diverse range of aviation emissions leads to questions about whether they can be placed on a common scale for comparison. There are several possible reasons for doing this. One is a technological - if there is a change in design or operation of an aircraft, does this change its climate impact? For example, contrails could be avoided by flying lower, but this would likely entail increased fuel use and increased $\mathrm{CO}_{2}$ emissions. Is this desirable? A second purpose might be in a legislative context, where the effects of non- $\mathrm{CO}_{2}$ emissions of aviation (or any other sector) are required to be taken into account to provide a fuller picture of the total impact. A related purpose is where companies provide consumers with the opportunity to pay towards schemes to offset the climate impact of their air travel, which could include the effect of non- $\mathrm{CO}_{2}$ emissions. 
$\mathrm{RF}$ is one potential index for making comparisons - indeed, one index is the ratio of the total forcing to the $\mathrm{CO}_{2}$-only forcing - this is sometimes called the Radiative Forcing Index (RFI) or, simply, a $\mathrm{CO}_{2}$ multiplier. In this usage, the climate impact of the $\mathrm{CO}_{2}$ is then multiplied by the RFI (which, according to Lee et al.'s (2009) estimates would be about 2 or 3 ) to get a total climate impact. RF and RFI are useful for looking at the cumulative effect of past aviation emissions, but less suited for looking at the future effects of current emissions. Hence, the use of the RFI has been heavily criticised (see e.g. Fuglestvedt et al. 2010) as it fails to account for the different lifetimes of the emissions (ranging from hours for contrails to millennia for much of the $\mathrm{CO}_{2}$ emitted); also it represents a fixed tax on fuel use (and hence $\mathrm{CO}_{2}$ emissions) which might encourage perverse behaviour whereby attempts are made to decrease $\mathrm{CO}_{2}$ emissions regardless of the impact on the non- $\mathrm{CO}_{2}$ emissions.

There are many difficulties in constructing a robust index (e.g., Fuglestvedt et al. (2010)). These include: (i) exactly what climate parameter should be compared? The $\mathrm{RF}$, the temperature change or perhaps some time-integral of these effects? (ii) Over what period should the parameters be calculated? Is it the climate impact in the decade or so following an emission, or should some longer-term impact be considered? (iii) How are the uncertainties in the effect of emissions taken into account? As will be shown, answers to (i) and (ii) have a profound influence on the perception of the relative importance of the $\mathrm{CO}_{2}$ and non- $\mathrm{CO}_{2}$ emissions. There is as yet no widely accepted way of comparing the climate effect of aircraft emissions and some choices, such as the time period of calculation, are value-laden decisions that must be made by policymakers.

\subsection{The Global Warming Potential and the Global Temperature-change Potential}

IPCC has, since its early assessments, presented an emissions index called the Global Warming Potential (GWP). If a pulse emission of, say, $1 \mathrm{~kg}$ of a gas is emitted into the atmosphere, the pulse decays (exponentially for many emissions) over some time period as it is removed from the atmosphere. The GWP represents the time-integral of the RF due of this decaying pulse - this means that the lifetimes of the gas, as well as its radiative strength are taken into account. It is normally presented as the ratio of a gas's GWP to that of $\mathrm{CO}_{2}$. The GWP (integrated over a 100 year "time horizon") was adopted for the Kyoto Protocol to the United Nations Framework Convention on Climate Change, to allow Protocol signatories to decide which, of a range of greenhouse gases, to control to meet its commitments. So, for example, the mass of methane emitted in a given year can be cast in " $\mathrm{CO}_{2}$-equivalence" terms by multiplying it by 28, the current estimate for methane's100-year GWP (Myhre et al., 2013). There have been a range of criticisms of the GWP as a concept and recognition of particular difficulties in calculating its values for short-lived species such as $\mathrm{NO}_{\mathrm{x}}$ (see Fuglestvedt et al. 2010 and references therein), but nevertheless it is widely used.

An alternative index, called the Global Temperature-change Potential (GTP) has also been proposed - this gives the temperature change at some specified time after a pulse emission into the atmosphere. The GTP has not achieved the level of acceptance of the GWP, but it may be more suited to certain types of climate policy (see Myhre et al., 2013) although it is also subject to criticism; nevertheless, it illustrates the 
influence of different choices in the design of emission indices. Because it looks at the temperature change some time after an emission, rather than integrating the effect of an emission over time, in general it indicates a lesser impact for the short-lived non$\mathrm{CO}_{2}$ emissions from aviation. The actual values of the GTP depend on the assumptions about the values of $\lambda$ and $C$ (see Section 2).

Tables 1 and 2 illustrate typical GWP and GTP values for aviation emissions, based on values in Fuglestvedt et al. (2010). It is emphasized that these values refer to the average effect of the present-day aircraft fleet - they cannot be applied to the effect of a single flight (for which, for example, the meteorological conditions may not allow contrail formation) and cannot be applied if there were significant changes to, for example, the altitudes or latitudes at which the fleet flies - the effect of $\mathrm{NO}_{\mathrm{x}}$ and contrails are highly dependent on where the emissions occur. Some information on the height and latitude dependence can be found in, for example, Grewe and Stenke (2007), Rädel and Shine (2009) and Søvde et al. (2014). Finally, the values presented in the Tables are subject to significant revisions as scientific understanding increases.

Each Table shows the values relative to $\mathrm{CO}_{2}$. The GWP is presented for three time horizons $(20,100,500$ years) which are the conventional values presented by IPCC. The GTP is presented for 20, 50 and 100 years, as this is felt to be more appropriate for such an index; in any case, for longer time periods, the non- $\mathrm{CO}_{2}$ emissions from aviation would quickly decay to zero, as they are so short-lived compared to $\mathrm{CO}_{2}$.

The values are presented as the effect of burning $1 \mathrm{~kg}$ of fuel, relative to the effect of the $\mathrm{CO}_{2}$ from this $1 \mathrm{~kg}$ of fuel. For each $\mathrm{kg}$ burnt, $3.16 \mathrm{~kg}$ of $\mathrm{CO}_{2}, 1.23 \mathrm{~kg}$ of $\mathrm{H}_{2} \mathrm{O}$ and $0.015 \mathrm{~kg}$ of $\mathrm{NO}_{2}$ are assumed to be emitted - the $\mathrm{NO}_{2}$ number is the most uncertain, as it is dependent on the way kerosene is burnt. Values are presented for "high $\mathrm{NO}_{\mathrm{x}}$ " and "low $\mathrm{NO}_{\mathrm{x}}$ " to reflect the range of $\mathrm{RF}$ values currently in the literature. The bottom 4 lines in the Tables show how much the $\mathrm{CO}_{2}$ effect has to be multiplied to incorporate the non- $\mathrm{CO}_{2}$ effects; it is given for the two $\mathrm{NO}_{\mathrm{x}}$ cases and with and without AIC, because of the particularly high uncertainty. These rows could be considered as an analogue for the RFI, but posed in terms of the future effect of present-day emissions.

Table 1 shows that for all components, the GWP decreases with time horizon - this is because the values are referenced to $\mathrm{CO}_{2}$, a significant component of which remains in the atmosphere for much longer than 500 years; hence the part of the $\mathrm{CO}_{2}$ pulse that remains in the atmosphere even at 500 years continues to contribute to (the integral of) RF, whereas the RF from the short-lived components have long since decayed to zero. It can be seen that the sign of the $\mathrm{NO}_{\mathrm{x}}$ component changes, as this is determined by the relative balance of the effect of the created ozone and the destroyed methane. The $\mathrm{CO}_{2}$ multiplier rows show different combinations of the total effect. This clearly illustrates that the multiplier to be applied to $\mathrm{CO}_{2}$ to account for the non$\mathrm{CO}_{2}$ emissions varies greatly depending on the chosen time horizon, and on which effects are considered, from 1.1 to 4.9 .

Table 2 shows the GTP drops off much more quickly with time horizon than the GWP (compare the 20 and 100 year values in Tables 1 and 2); because of the nature of the GTP, it retains less memory of short-lived effects than the GWP. $\mathrm{NO}_{\mathrm{x}}$ values are generally negative, because the cooling due to methane dominates over the warming 
due to ozone. Fuglestvedt et al. (2010) discuss the reasons for the behaviour of these values. In general, the $\mathrm{CO}_{2}$ multiplier values are much smaller than for the GWP and indeed, can be less than unity for some cases, where the methane-induced cooling has a strong influence. In the cases given, the multiplier ranges from 0.4 to 1.6.

\section{CONCLUSION}

Aviation causes climate change as a result of its emissions of $\mathrm{CO}_{2}$, oxides of nitrogen, aerosols and water vapour. While the RF due to changes in $\mathrm{CO}_{2}$ is as wellcharacterised as those from other sources due to human activity, there are formidable difficulties in estimating the non- $\mathrm{CO}_{2}$ forcings - this is particularly the case for the aviation-induced changes in cloudiness (AIC). The best-estimate of total radiative forcing to 2005, from aviation, using values from the most recent comprehensive assessment (Lee et al. 2009) is $55 \mathrm{~mW} \mathrm{~m}^{-2}$ excluding AIC and $78 \mathrm{~mW} \mathrm{~m}^{-2}$ including it, with an uncertainty of at least a factor of two; these values are likely broadly appropriate for 2011 given recent developments in understanding. The 2005 aviation $\mathrm{CO}_{2} \mathrm{RF}$ represents about $1.6 \%$ of the total $\mathrm{CO}_{2}$ forcing from all human activities. It is estimated that, including the non- $\mathrm{CO}_{2}$ effects, aviation contributes between 1.3 and $14 \%$ of the total RF due to all human activities.

Two distinct methods for comparing the future impact of present-day aviation emissions are presented - the Global Warming Potential and the Global Temperaturechange Potential. The perception of the relative importance of the non- $\mathrm{CO}_{2}$ emissions, relative to $\mathrm{CO}_{2}$ depends considerably on the chosen method and the parameters chosen within that method. Of particular importance is the choice of the time-scale over which the effects are compared - in general, the longer the time scale that is chosen, the more important $\mathrm{CO}_{2}$ becomes, relative to the non- $\mathrm{CO}_{2}$ emissions.

Improvement in estimates of RF will require advances in our understanding of atmospheric processes, better techniques for numerical modelling of these processes and more detailed, and sustained, observations, using both in situ and remote sensing techniques.

\section{REFERENCES}

Archer D and Brovkin V. The millennial atmospheric lifetime of anthropogenic $\mathrm{CO}_{2}$ Climatic Change 2008; 90:283-297.

Boer GJ and Yu B. Climate sensitivity and response. Climate Dynamics 2003; 21:415-429.

Boucher O, Randall D, Artaxo P, Bretherton C, Feingold G, Forster P, Kerminen VM, Kondo Y, Liao H, Lohmann U, Rasch P, Satheesh SK, Sherwood S, Stevens B and Zhang XY. Clouds and Aerosols. In: Climate Change 2013: The Physical Science Basis. Contribution of Working Group I to the Fifth Assessment Report of the Intergovernmental Panel on Climate Change (Stocker TF, Qin D, Plattner G-K, Tignor M, Allen SK, Boschung J, Nauels A, Xia Y, Bex V and Midgley PM (eds.)) . Cambridge University Press, Cambridge UK, 2013. 
Brasseur GP, Cox RA, Hauglustaine D, Isaksen I, Lelieveld J, Lister DH, Sausen R, Schumann U, Wahner A and Wiesen P. European scientific assessment of the atmospheric effects of aircraft emissions. Atmos. Environ. 1998; 32:2329-2418.

Burkhardt U and Kärcher B. Global radiative forcing from contrail cirrus. Nature Climate Change. 2011; 1:54-58.

Dietmuller S, Ponater M, Sausen R, Hoinka KP and Pechtl S. Contrails, natural clouds, and diurnal temperature range. J.Climate. 2008; 21: 5061-5075.

Forster P, Ramaswamy V, Artaxo P, Berntsen T, Betts R, Fahey DW, Haywood J, Lean J, Lowe DC, Myhre G, Nganga J, Prinn R, Raga G, Schulz M and Van Dorland $\mathrm{R}$. Changes in atmospheric constituents and in radiative forcing. Climate Change 2007: The Physical Science Basis. Contribution of Working Group I to the Fourth Assessment Report of the Intergovernmental Panel on Climate Change [Solomon S, Qin D, Manning M, Chen Z, Marquis M, Averyt KB, Tignor M and Miller HL (Eds.)], Cambridge University Press, Cambridge, United Kingdom 2007.

Fuglestvedt JS, Shine KP, Berntsen T, Cook J, Lee DS, Stenke A, Skeie RB, Velders GJM and Waitz IA. Transport Impacts on Atmosphere and Climate: Metrics. Atmos. Environ. 2010; 44:4648-4677.

Gauss M, Isaksen ISA, Wong $\mathrm{S}$ and Wang W.-C. Impact of $\mathrm{H}_{2} \mathrm{O}$ emissions from cryoplanes and kerosene aircraft on the atmosphere. J. Geophys. Res., 2003;

108:4304.

Gettelman A and Chen C. The climate impact of aviation aerosols, Geophys. Res. Lett., 2013; 40:2785-2789.

Grewe V and Stenke A. AirClim: an efficient tool for climate evaluation of aircraft technology. Atmos. Chem. Phys. 2008; 8:4621-4639.

Hartmann DL. Global Physical Climatology. Academic 1996.

IPCC. Aviation and the global atmosphere. Penner JE, Lister DH, Griggs DJ, Dokken DJ and McFarland M (Eds.), Intergovernmental Panel on Climate Change. Cambridge University Press, Cambridge, UK 1999.

IPCC. Climate Change 2013: The Physical Science Basis. Contribution of Working Group I to the Fifth Assessment Report of the Intergovernmental Panel on Climate Change . Stocker TF, Qin D, Plattner G-K, Tignor M, Allen SK, Boschung J, Nauels A, Xia Y, Bex V and Midgley PM (eds.). Cambridge University Press, Cambridge, UK. 2013.

Lee DS, Fahey DW, Forster PM, Newton PJ, Wit RCN, Lim LL, Owen B and Sausen R. Aviation and global climate change in the 21st century. Atmos. Environ. 2009; 43:3520-3537

Lee DS, Pitari G, Berntsen T., Grewe V, Gierens K, Penner JE, Petzold A, Prather M, Schumann U, Bais A, Iachetti D and Lim LL. Transport impacts on atmosphere and climate: aviation, Atmos. Environ. 2010; 44:4678-4734.

Matthews WH, Kellogg WW and Robinson GD (Eds). Man's impact on climate, MIT Press, Cambridge Mass, 1971. 
Minnis P, Young DF, Garber DP, Nguyen L, Smith WLJ and Palikonda R. Transformation of contrails into cirrus during SUCCESS. Geophys. Res. Lett. 1998; 25:1157-1160.

Myhre G and Stordal F. On the tradeoff of the solar and thermal infrared radiative impact of contrails. Geophys. Res. Lett. 2001; 28:3119-3122.

Myhre G, Shindell D, Bréon F-M, Collins W, Fuglestvedt J, Huang J, Koch D, Lamarque J-F, Lee D, Mendoza B, Nakajima T, Robock A, Stephens G, Takemura T and Zhang H. Anthropogenic and Natural Radiative Forcing. In: Climate Change 2013: The Physical Science Basis. Contribution of Working Group I to the Fifth Assessment Report of the Intergovernmental Panel on Climate Change (Stocker TF, Qin D, Plattner G-K, Tignor M, Allen SK, Boschung J, Nauels A, Xia Y, Bex V and P.M. Midgley PM (eds.)) . Cambridge University Press, Cambridge UK, 2013.

Ponater M, Pechtl S, Sausen R, Schumann U and Hüttig G. Potential of the cryoplane technology to reduce aircraft climate impact: A state-of-the-art assessment. Atmos. Environ. 2006; 40:6928-6944.

Rädel G and Shine KP. Radiative forcing by persistent contrails and its dependence on cruise altitudes. J. Geophys. Res. 2008; 113:D07105.

Rap A, Forster PM, Haywood JM, Jones A and Boucher O. Estimating the climate impact of linear contrails using the UK Met Office climate model. Geophys. Res. Lett. 2010; 37:L20703.

Righi M, Hendricks J and Sausen R. The global impact of the transport sectors on atmospheric aerosol: simulations for year 2000 emissions. Atmos. Chem. Phys. 2013; 13:9939-9970.

Søvde OA, Matthes S, Skowron A, Iachetti D, Lim L, Owen B, Hodnebrog Ø, Di Genova G, Pitari G, Lee DS, Myhre G and Isaksen ISA. Aircraft emission mitigation by changing route altitude: A multi-model estimate of aircraft NOx emission impact on $\mathrm{O}_{3}$ photochemistry, Atmos. Environ. 2014; 95:468-479.

Spangenberg DA, Minnis P, Bedka ST, Palikonda R, Duda DP and Rose FG. Contrail radiative forcing over the Northern Hemisphere from 2006 Aqua MODIS data, Geophys. Res. Lett. 2013; 40:595-600.

Stuber N, Forster P, Rädel G and Shine KP. The importance of the diurnal and annual cycle of air traffic for contrail radiative forcing. Nature 2006; 441:864-867.

Travis DJ, Carleton AM and Lauritsen RG. Regional variations in US diurnal temperature range for the 11-14 September 2001 aircraft groundings: Evidence of jet contrail influence on climate. J. Climate 2004; 17:1123-1134.

Wilcox LJ, Shine KP and Hoskins BJ. Radiative forcing by aviation water vapour emissions. Atmos. Environ. 2012; 63:1-13. 


\begin{tabular}{|c|c|c|c|}
\hline & \multicolumn{3}{|c|}{ Time Horizon (years) } \\
\hline & 20 & 50 & 100 \\
\hline $\mathrm{NO}_{\mathrm{x}}$ (high estimates) & -0.29 & -0.09 & 0.01 \\
\hline $\mathrm{NO}_{\mathrm{x}}$ (low estimates) & -0.85 & -0.30 & -0.01 \\
\hline Contrails & 0.21 & 0.04 & 0.03 \\
\hline Aviation-induced cloud (AIC) & 0.64 & 0.11 & 0.09 \\
\hline Water vapour & 0.08 & 0.01 & 0.01 \\
\hline $\mathrm{CO}_{2}$-multiplier $\left(\mathrm{NO}_{\mathrm{x}}\right.$ high, no AIC) & 1.0 & 1.0 & 1.1 \\
\hline $\mathrm{CO}_{2}$-multiplier $\left(\mathrm{NO}_{\mathrm{x}}\right.$ high, including $\left.\mathrm{AIC}\right)$ & 1.6 & 1.1 & 1.1 \\
\hline $\mathrm{CO}_{2}$-multiplier $\left(\mathrm{NO}_{\mathrm{x}}\right.$ low, no AIC) & 0.4 & 0.7 & 1.0 \\
\hline $\mathrm{CO}_{2}$-multiplier $\left(\mathrm{NO}_{\mathrm{x}}\right.$ low, including $\left.\mathrm{AIC}\right)$ & 1.1 & 0.9 & 1.1 \\
\hline
\end{tabular}
fuel burnt. The bottom 4 rows show how much the $\mathrm{CO}_{2}$ effect, for each $\mathrm{kg}$ of fuel burnt, should be multiplied to account for the non- $\mathrm{CO}_{2}$ effects.

\begin{tabular}{|c|c|c|c|}
\hline & \multicolumn{3}{|c|}{ Time Horizon (years) } \\
\hline & 20 & 100 & 500 \\
\hline NO $_{x}$ (high estimates) & 0.68 & 0.10 & 0.03 \\
\hline $\mathrm{NO}_{\mathrm{x}}($ low estimates $)$ & 0.17 & -0.003 & -0.001 \\
\hline Contrails & 0.74 & 0.21 & 0.064 \\
\hline Aviation-induced cloud (AIC) & 2.2 & 0.63 & 0.19 \\
\hline Water vapour & 0.27 & 0.078 & 0.023 \\
\hline $\mathrm{CO}_{2}$-multiplier $\left(\mathrm{NO}_{\mathrm{x}}\right.$ high, no AIC) & 2.7 & 1.4 & 1.1 \\
\hline $\mathrm{CO}_{2}$-multiplier ( $\mathrm{NO}_{\mathrm{x}}$ high, including AIC) & 4.9 & 2.0 & 1.3 \\
\hline $\mathrm{CO}_{2}$-multiplier $\left(\mathrm{NO}_{\mathrm{x}}\right.$ low, no AIC) & 2.2 & 1.3 & 1.1 \\
\hline $\mathrm{CO}_{2}$-multiplier $\left(\mathrm{NO}_{\mathrm{x}}\right.$ low, including AIC) & 4.4 & 1.9 & 1.3 \\
\hline
\end{tabular}

Table 2: Estimates of the Global Temperature-change Potential for three time horizons for aviation emissions, relative to $\mathrm{CO}_{2}$ for the present-day aviation fleet for each $\mathrm{kg}$ of fuel burnt. The bottom 4 rows show how much the $\mathrm{CO}_{2}$ effect, for each $\mathrm{kg}$ of fuel burnt, should be multiplied to account for the non- $\mathrm{CO}_{2}$ effects.

Table 1: Estimates of the Global Warming Potential for three time horizons for aviation emissions, relative to $\mathrm{CO}_{2}$ for the present-day aviation fleet for each $\mathrm{kg}$ of

13 
Aviation Radiative Forcing Components in 2005

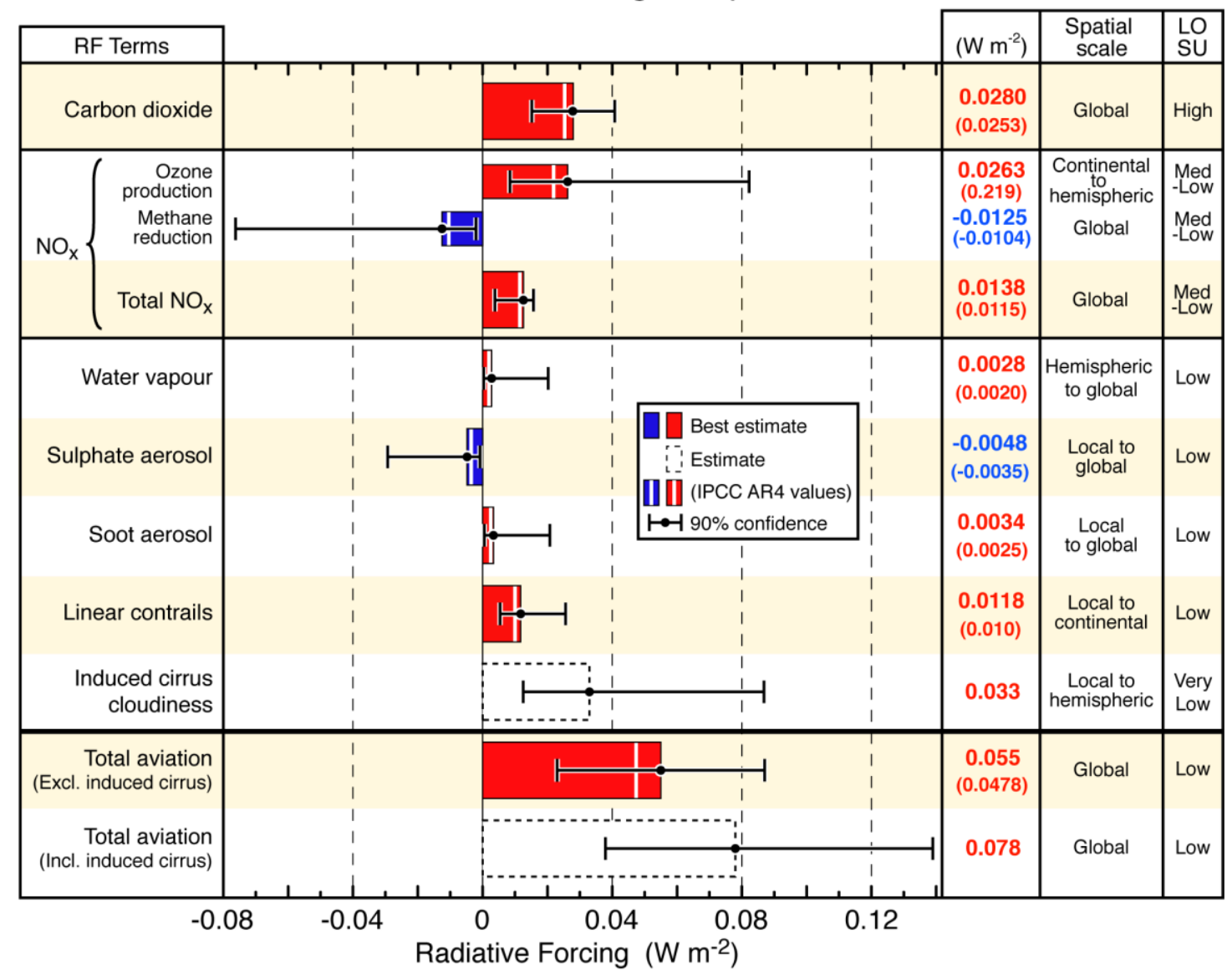

Figure 1. Global-mean radiative forcing components due to aviation for 2005, relative to preindustrial times. Coloured bars represent best estimates (except for the case of aviation-induced cloud changes (AIC) where a best-estimate cannot be given). Values indicated by the white lines within the bars are from Forster et al. (2007). The induced cloudiness (AIC) estimate includes linear contrails. Numerical values are given on the right for both Forster et al. (2007) (in parentheses) and for Lee et al. (2009). Error bars represent the $90 \%$ likelihood range for each estimate. The best estimate value of total radiative forcing from aviation is shown with and without AIC. The spatial scale of each radiative forcing and its level of scientific understanding (LOSU) are shown in the columns on the right. Reproduced from Lee et al. (2009) (C) Elsevier. 


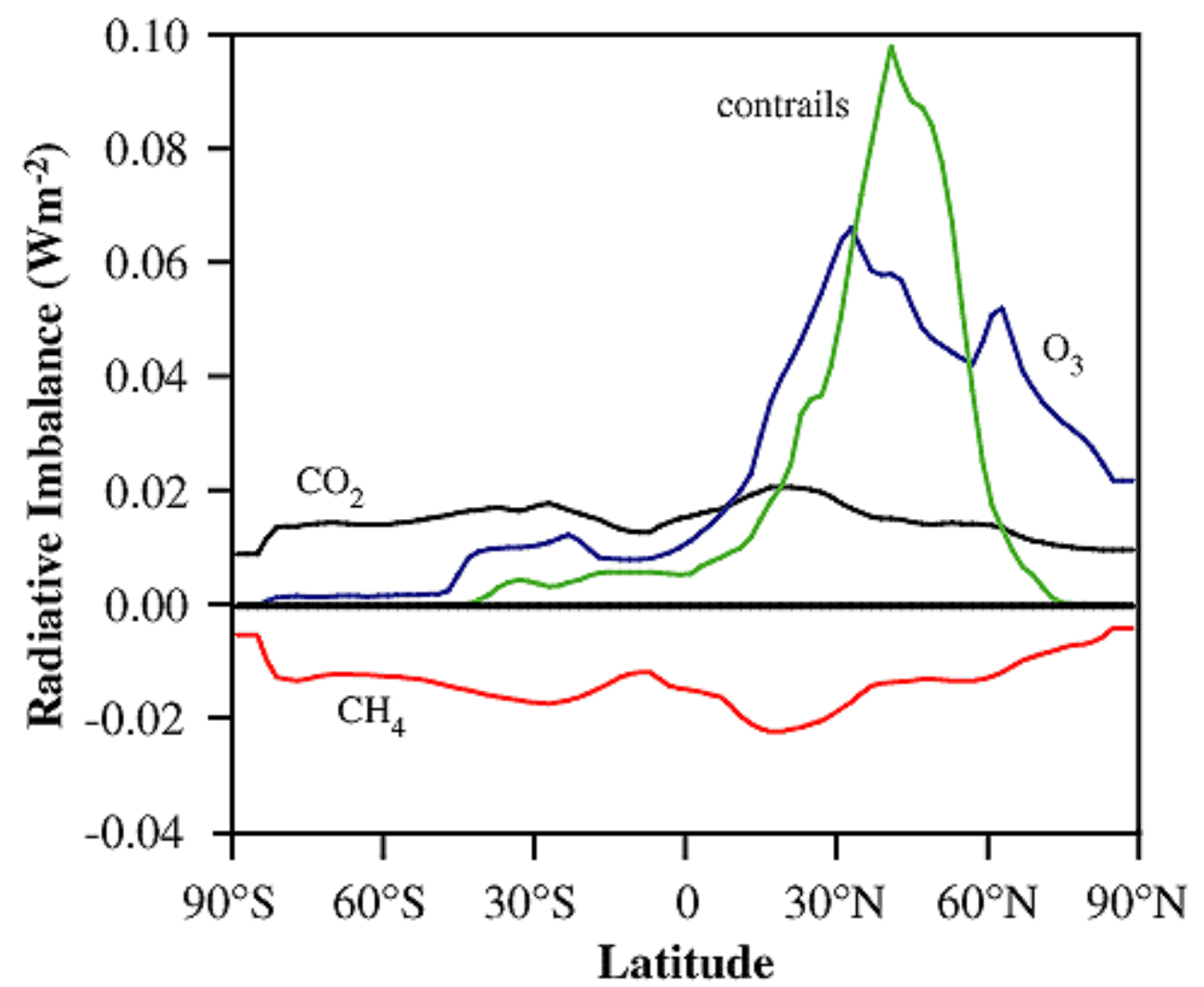

\section{1}

Figure 2: Radiative forcing as a function of latitude for global aviation in 1992, relative to pre-industrial times, for a number of aviation-induced forcings. Note that the global-mean of these values will not correspond to those in Figure 1, as they are for a different period and because of improvements in understanding. Reproduced from IPCC (1999) () Cambridge University Press. 